CHANNEL CAPACITY, SCHIZOPHRENIA AND DOPAMINE

DeAR SIR,

In his recent article (Journal, March 1979, 134, 225-35) C. D. Frith deals with the origins of schizophrenic symptomatology as arising from a failure of restraint of preconscious material from entering consciousness. Like Broadbent, he attributes schizophrenic symptomatology to channel overload somewhere in the brain. The question is where?

Because the CNS is such a complicated matrix of feedback systems, it seems improbable that psychological analysis of schizophrenia will ever unambiguously pinpoint a defect in a specific system. The question therefore needs to be considered at a neurophysiological level and requires electrophysiological analysis with specific reference to the total information transmitted through various brain regions, using the analytical techniques of information theory. The methods of evoked potential analysis and Fourier analysis of the time and space variation of neural activity in various brain regions offer some hope of attacking these problems, although present techniques may well prove inadequately discriminating to detect a reliable difference between schizophrenics and normals.

Some indirect support for channel overload hypotheses can be concluded from recent work on the role of dopamine in the CNS. This work indicates that dopaminergic activity accelerates the rate of information processing in the cortex (Wright and Craggs, 1979, Experimental Neurology, 65, 42-52) and as antipsychotic medications appear to be dopamine blockers it follows that their action may be regarded as reducing information overload on the channel.

Department of Psychiatry, J. J. WRIGHT

University of Auckland,

School of Medicine,

New Zealand

\section{DRUG INTERACTION BETWEEN HALOPERIDOL AND METHYLDOPA}

DEAR SIR,

This vexing drug interaction is little known, as we have found only two publications (see below) where it was mentioned, haloperidol being given concurrently with methyldopa. We have had such a case.

This 74-year-old white Caucasian female was admitted for the first time to a state hospital when she was in her early twenties. Childhood and adolescence were uneventful, she married at 20, had three children and was described by her relatives to be slovenly, careless and lazy. The diagnosis at admission was schizophrenia, paranoid type: she was suspicious, worried that everybody wanted to steal from her apartment and finally that her husband wanted to kill her. She was treated with the therapeutic methods of the time. Her condition remained psychotic, but she was manageable.

Lately she had the delusion of pregnancy and that she was about 'to deliver a baby'. As she developed a slight arterial hypertension, she was given methyldopa $250 \mathrm{mg}$ b.i.d. by the treating internist, while the psychiatrist treated her with thioridazine $50 \mathrm{mg}$ b.i.d. and then instead with haloperidol $2 \mathrm{mg}$ b.i.d. because the patient developed ventricular premature beats. After several days she became progressively irritable, aggressive, assaulted other patients and staff, was unmanageable. Although the dose of haloperidol was increased to $24 \mathrm{mg}$ per day, this state of permanent restlessness and assaultiveness did not subside. When the methyldopa was discontinued, and replaced with hydrochlorothiazide $50 \mathrm{mg}$ daily, the patient improved dramatically: her aggressivity and assaultiveness subsided, her paranoid ideation became much less intense and she became again easily manageable. The daily dose of haloperidol was rapidly reduced and is now only $1 \mathrm{mg}$ b.i.d.

This drug interaction is not mentioned in any of the literature inserted with these two widely used drugs. We must not overlook that the older a psychiatric patient becomes, the more likely he is to be treated by a physician for an intercurrent arterial hypertension; therefore it is important to be aware of this possible drug interaction.

IgNAT NADEL

Kingsboro Psychiatric Center, Morton Wallach

681 Clarkson Avenue,

Brooklyn,

New York 11203

\section{References}

Chouinard, G., Pinard, G., Serrano, M. \& Treteault, L. (1973) Potentiation of haloperidol by alphamethyldopa in the treatment of schizophrenic patients. Current Therapeutic Research, 15, 473-83.

Thornton, William F. (1976) Dementia induced by methyldopa with haloperidol. New England Journal of Medicine, 294, 1222.

\section{CHEAPER CARE OF PARASUICIDES}

DEAR SIR,

In their letter entitled 'Cheaper Care of Parasuicides' (Journal, July 1979, 135, 92-93) Kennedy and Oswald ask whether the specialist psychiatric services recommended in the Hill report and developed in the Regional Poisoning Treatment 